\title{
Registros de enredamentos de baleias-franca, Eubalaena australis (Cetacea, Mysticeti), na temporada reprodutiva de 2010, em Santa Catarina, Brasil
}

\author{
Mônica Pontalti \\ Mônica Danielski* \\ Instituto Baleia Franca (IBF) \\ Garopaba - SC, Brasil \\ *Autor para correspondência \\ monicadanielski@gmail.com \\ Rua Pará 299, Próspera, CEP 88811-750, Criciúma - SC, Brasil
}

Submetido em 30/11/2010

Aceito para publicação em 14/03/2011

\section{Resumo}

Baleias-francas (Eubalaena australis) sofrem diferentes pressões antrópicas como poluição, tráfego de embarcações e emalhe em redes de pesca. Casos de enredamentos em baleias-francas são crescentes no litoral sul de Santa Catarina, podendo levar a encalhes e a morte. Durante a temporada reprodutiva de 2010, foram registrados seis casos de emalhes em indivíduos juvenis e adultos. É necessária a criação de medidas de regulamentação da pesca durante a temporada reprodutiva de baleias-francas em Santa Catarina, considerando as peculiaridades da pesca na região com o objetivo de minimizar as injúrias causadas às baleias e evitar prejuízos às comunidades pesqueiras locais.

Palavras-chave: Baleias-franca, Enredamentos, Santa Catarina

\section{Abstract}

Entanglements of right whales, Eubalaena australis (Cetacea, Mysticeti), in the 2010 breeding season in Santa Catarina state, Brazil. Right whales (Eubalaena australis) have been suffering with anthropogenic activities such as pollution, marine traffic and entanglement in fishing nets. The entanglement of right whales grows each breeding season on the southern coast of Santa Catarina state, and can cause strands and even death. During the 2010 breeding season, six entanglements among immature and adult whales were recorded. In most of the cases, the whales kept swimming slowly and didn't want to approximate the whale watching boat. Fishing activities in the area during the right whale breeding season need to be regularized to avoid conflicts and injuries to the whales.

Key words: Entanglements, Santa Catarina state, southern right whale 
Durante a temporada reprodutiva de 2010 (julho a novembro), o Instituto Baleia Franca realizou monitoramentos embarcados a partir de um bote inflável com fundo rígido de $9 \mathrm{~m}$ próprio para turismo de observação de baleias equipado com dois motores de $90 \mathrm{HP}$. A cada cruzeiro, um observador utilizava a embarcação como plataforma de oportunidade para coleta de dados. Ao longo de toda a temporada, seis animais diferentes foram identificados com redes de pesca presas ao seu corpo, sendo dois deles fotografados (Tabela 1; Figuras 1 e 2). A diferenciação dos animais foi feita através do padrão de distribuição das calosidades em sua cabeça, além de marcas naturais presentes ao longo corpo.

O emalhe em redes de pesca é uma causa significante de injúria e mortalidade em muitas populações de mamíferos marinhos por todo o mundo (JOHNSON et al., 2005). Populações de baleias-francas sofrem com emalhes em redes de pesca nos oceanos Atlântico e Pacífico.

Estudos recentes mostram que $71,9 \%$ da população de baleias-francas do Atlântico Norte (Eubalaena glacialis) sofreram emalhamento pelo menos uma vez durante sua vida. Estudos sobre emalhes de baleiasfranca do Atlântico Sul, principalmente na população que freqüenta o sul do Brasil, são escassos. Greig et al. (2001), analisando os registros de encalhes de baleiasfrancas no litoral do Rio Grande do Sul e Santa Catarina entre 1977 e 1991, detectaram que aproximadamente $15 \%$ dos encalhes de animais mortos foram provenientes de atividades antropogênicas como colisões com embarcações e emalhes em redes de pesca. Przbylski e Monteiro-Filho (2001) citam um caso de emalhe de baleia-franca em rede de pesca no litoral paranaense. No litoral catarinense, um caso de enredamento foi registrado na Praia do Luz (Imbituba, SC) em agosto de 2005. O animal tinha a rede presa nas calosidades da região rostral e foi reavistado ainda com rede no mês de outubro do mesmo ano (DANIELSKI et al., 2006). Na temporada reprodutiva de 2009, Pontalti e Prinzler (2010) registraram cinco casos de emalhes de indivíduos adultos de baleias-francas em diferentes baías das cidades de Garopaba e Imbituba no litoral sul catarinense.

Em Santa Catarina, as baleias francas são encontradas próximas à costa, em águas rasas e calmas,

TABELA 1: Características das avistagens de baleias-franca enredadas na temporada reprodutiva de 2010, nas praias da APA da Baleia Franca no litoral de Santa Catarina, Brasil.

\begin{tabular}{|c|c|c|c|c|}
\hline Identificação & $\begin{array}{c}\text { Data da } \\
\text { avistagem }\end{array}$ & Local da avistagem & Localização da rede & Observações \\
\hline $\begin{array}{l}\text { BF } 01 \text { Juvenil } \\
\text { solitário }\end{array}$ & $23 / 07 / 2010$ & $\begin{array}{l}\text { Praia do Rosa } \\
\text { Imbituba-SC }\end{array}$ & Calosidades da cabeça & $\begin{array}{l}\text { Indivíduo aproximou-se da em- } \\
\text { barcação e realizou saltos. }\end{array}$ \\
\hline $\begin{array}{l}\text { BF } 02 \text { Adulto de um } \\
\text { grupo de acasala- } \\
\text { mento }\end{array}$ & $28 / 08 / 2010$ & $\begin{array}{l}\text { Praia do Siriú } \\
\text { Garopaba-SC }\end{array}$ & $\begin{array}{l}\text { Orifícios respiratórios } \\
\text { até a calosidade da ex- } \\
\text { tremidade frontal da } \\
\text { cabeça }\end{array}$ & $\begin{array}{l}\text { A rede prejudicava a respiração } \\
\text { do animal, que se deslocava len- } \\
\text { tamente e permanecia afastado } \\
\text { do grupo. }\end{array}$ \\
\hline $\begin{array}{l}\text { BF03 Adulto de um } \\
\text { grupo de acasala- } \\
\text { mento }\end{array}$ & $29 / 08 / 2010$ & $\begin{array}{l}\text { Praia da Vigia } \\
\text { Garopaba-SC }\end{array}$ & Calosidades da cabeça & $\begin{array}{l}\text { Indivíduo não se aproximou da } \\
\text { embarcação. }\end{array}$ \\
\hline $\begin{array}{l}\text { BF04 } \\
\text { Fêmea adulta }\end{array}$ & 07/09/2010 & $\begin{array}{l}\text { Praia do Siriú } \\
\text { Garopaba-SC }\end{array}$ & $\begin{array}{l}\text { Calosidade frontal da } \\
\text { cabeça e enrolada ao } \\
\text { longo do corpo. }\end{array}$ & $\begin{array}{l}\text { Indivíduo não se aproximou da } \\
\text { embarcação e deslocava-se len- } \\
\text { tamente. }\end{array}$ \\
\hline $\begin{array}{c}\text { BF05 } \\
\text { Fêmea adulta }\end{array}$ & 05/11/2010 & $\begin{array}{l}\text { Praia da Guarda } \\
\text { Paulo Lopes-SC }\end{array}$ & Cabeça & $\begin{array}{l}\text { Indivíduo não se aproximou da } \\
\text { embarcação. Foi possível ver } \\
\text { peixes presos na rede, sugerindo } \\
\text { um enredamento recente. }\end{array}$ \\
\hline $\begin{array}{c}\text { BF06 } \\
\text { Fêmea adulta }\end{array}$ & 07/11/2010 & $\begin{array}{l}\text { Praia da Guarda } \\
\text { Paulo Lopes-SC }\end{array}$ & Cabeça & $\begin{array}{l}\text { Indivíduo não se aproximou da } \\
\text { embarcação. }\end{array}$ \\
\hline
\end{tabular}




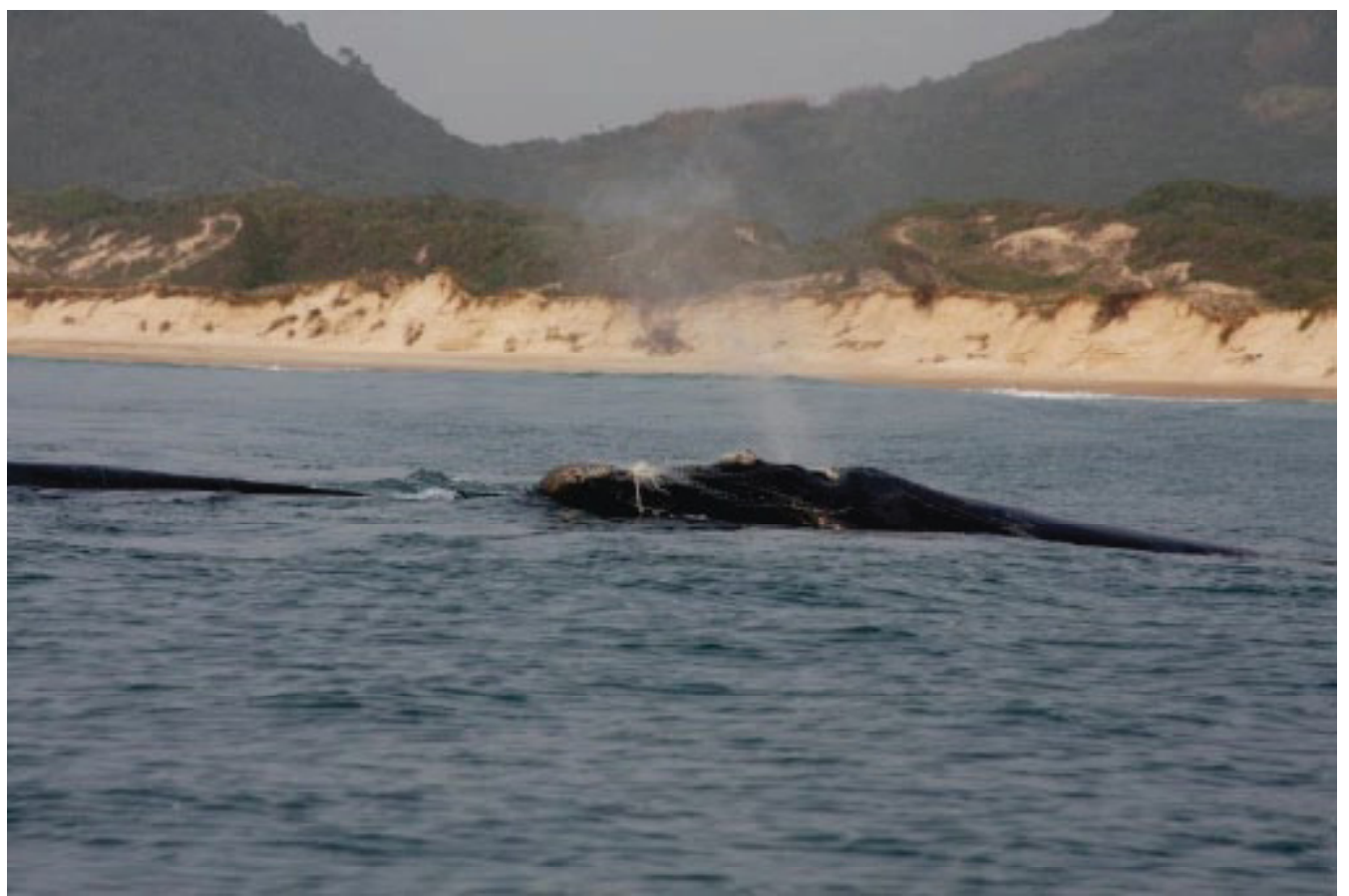

FIGURA 1: Indivíduo adulto de baleia-franca avistado com rede presa à cabeça em 28/08/2010 na Praia do Siriú, Garopaba, Santa Catarina.

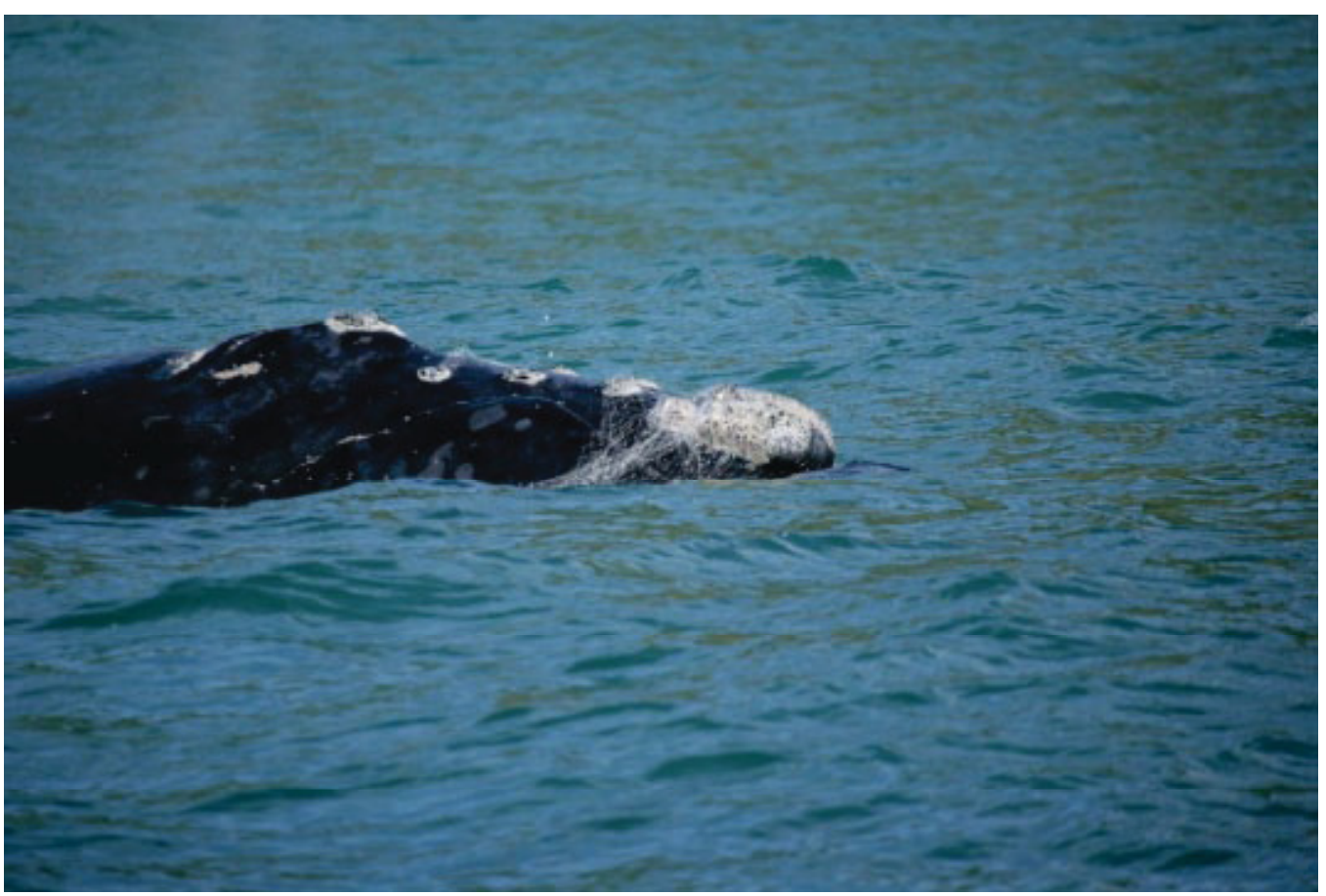

FIGURA 2: Fêmea adulta de baleia-franca avistada com rede presa à cabeça e corpo em 07/09/2010 na Praia do Siriú, Garopaba, Santa Catarina. 
favoráveis ao acasalamento e cria de filhotes, sendo que em agosto e setembro ocorre um aumento da frequência de filhotes nessas águas, podendo estar presentes em pelo menos 45\% dos grupos (SIMÕES- LOPES et al., 1992). Por possuir hábitos preferencialmente costeiros, a espécie torna-se bastante vulnerável às atividades humanas (SIMÕES- LOPES et al., 1992; LODI et al., 1996).

Segundo Cimardi (1996), umas das principais preocupações no que se refere às baleias-francas em Santa Catarina são os enredamentos em redes de pesca, onde a atividade pesqueira é intensa. A maioria dos animais adultos consegue arrebentar as redes de pesca e geralmente arrastam pedaços de cordas, na maioria das vezes, presos à cabeça (HETZEL; LODI, 1993). Entretanto, a grande preocupação é com o enredamento de filhotes, que podem ser sufocados e até mesmo morrer (PALAZZO et al., 1999).

A pesca artesanal é ainda uma das maiores fontes de sustentação de muitas comunidades costeiras e é caracterizada pelo uso de apetrechos simples e embarcações de pequeno porte. Tais instrumentos são comumente causadores de emalhes acidentais de pequenos e grandes cetáceos. A combinação do fator de importância da pesca artesanal, associado aos hábitos costeiros das baleias-francas em Santa Catarina, gera um conflito iminente durante a temporada reprodutiva da espécie no litoral. Lodi et al. (1996) recomendam que as redes de espera sejam recolhidas quando forem detectadas baleias nas proximidades das áreas de pesca. Faz-se necessário a criação de medidas de regulamentação da atividade pesqueira durante a temporada reprodutiva de baleias-francas no litoral sul de Santa Catarina, levando em consideração as peculiaridades da pesca na região, com o objetivo de minimizar as injúrias causadas às baleias e evitar prejuízos às comunidades pesqueiras locais.

\section{Referências}

CIMARDI, V. A. Mamíferos de Santa Catarina. Florianópolis: FATMA, 1996. 302 p.

DANIELSKI, M.; MARTIN, P.; VOIETTA, F.; GARCIA, A Registro de enredamento de baleia-franca (Eubalaena australis) em Santa Catarina, região sul do Brasil. 2005. In: REUNION INTERNACIONAL SOBRE EL ESTUDIO DE MAMIFEROS ACUATICOS, 1, 2006, Mérida. Actas... Mérida: SOMMEMASOLAMAC, 2006.

GREIG, A.; SECCHI, E.; ZERBINI, A.; DALLA ROSA, L. Stranding events of southern right whales, Eubalaena australis, in southern Brazil. Journal of Cetaceans Research and Management, Cambridge, Special Issue, v. 2, p. 157-160, 2001.

HETZEL, B.; LODI, L. Baleias, botos e golfinhos: guia de identificação para o Brasil. Rio de Janeiro: Nova Fronteira, 1993. $279 \mathrm{p}$.

JOHNSON, A.; SALVADOR, G.; KENNEY, J.; ROBBINS, J.; KRAUS, S.; LANDRY, S.; CLAPHAM, P. Fishing gear involved in entanglements of right and humpback whales. Marine Mammal Science, Hartford, v. 21, n. 4, p. 635-645, 2005.

LODI, L.; SICILIANO, S.; BELLINI, C. Ocorrências e conservação de baleias-francas-do-sul, Eubalaena australis, no litoral do Brasil. Papéis Avulsos Departamento Zoologia, São Paulo, v. 39, n. 17, p. 307-328, 1996

PALAZZO, J. T.; FLORES, P. A. C.; GROCH, K. R.; OTT, P. H. First resighting of a southern right whales (Eubalaena australis) in Brazilian waters and an indicative of a three-year return and calving interval. In: BIENNIAL CONFERENCE ON THE BIOLOGY OF MARINE MAMMALS, 13, 1999, Maui. Abstracts... Maui: BMM, 1999. p. 143

PONTALTI, M.; PRINZLER, D. Registros de enredamento de baleias-francas (Eubalaena australis) em Santa Catarina, Região Sul do Brasil. In: CONGRESSO BRASILEIRO DE OCEANOGRAFIA, IV, 2010, Rio Grande. Resumos... Rio Grande: ABO, 2010. Resumo 133.

PRZBYLSKI, C. B.; MONTEIRO-FILHO, E. L. A. Interação entre pescadores e mamíferos marinhos no litoral do estado do Paraná Brasil. Biotemas, Florianópolis, v. 14, n. 2, p. 141-156, 2001.

SIMÕES-LOPES, P. C.; PALAZZO, J. T.; XIMENEZ, A. Identificação, movimentos e aspectos biológicos da baleia-franca austral (Eubalaena australis) na costa do Brasil. In: REUNION DE ESPECIALISTAS EM MAMÍFEROS AQUÁTICOS DEL AMERICA DEL SUL, III, 1992, Montevidéo. Resumens... Montevidéo: SOMMEMA-SOLAMAC, 1992. Resumo 62. 